\title{
Currents technologies at the service of the diabetic patients: State of the art
}

\author{
Andrès $E^{1,2 *}$, Jeandidier $N^{3}$, Meyer $L^{3}$, Bahougne $T^{3}$, Zulfiqar $A A^{1,2}$, Talha $S^{2,4}$, Hajjam $M^{5}$ and Hajjam El Hassani $A^{6}$ \\ ${ }^{1}$ Service de Médecine Interne, Diabète et Maladies Métaboliques de la Clinique Médicale B, Hôpitaux Universitaires de Strasbourg, 1, porte de l’Hôpital, 67091 \\ Strasbourg cedex, France \\ ${ }^{2}$ Equipe de recherche EA 3072 "Mitochondrie, Stress oxydant et Protection musculaire", Faculté de Médecine de Strasbourg, Université de Strasbourg (Unistra), \\ Strasbourg, France \\ ${ }^{3}$ Service d'Endocrinologie et de Diabétologie de la Clinique Médicale B, Hôpitaux Universitaires de Strasbourg, Strasbourg, France \\ ${ }^{4}$ Service de Physiologie et d'Explorations Fonctionnelles, Hôpitaux Universitaires de Strasbourg, Strasbourg, France \\ ${ }^{5}$ Predimed Technology, Strasbourg, France \\ ${ }^{6}$ Equipe de recherche EA 4662 "Nanomédecine, Imagerie, Thérapeutiques", Université de Technologie de Belfort-Montbéliard (UTBM), Belfort-Montbéliard, \\ France
}

\begin{abstract}
In recent years, several technological innovations have become part of the daily lives of diabetic patients as non-invasive glucose sensors, intelligent insulin pumps, artificial pancreas, telemedicine, and artificial intelligence. A review of the literature dedicated to these technologies supports the efficacy of these latter in diabetic patients. Mainly, these technologies have shown a beneficial effect on diabetes management with an improvement of: blood glucose control, with a significant reduction in HbA1c; patient ownership of the disease; patient adherence to therapeutic and hygiene-dietary measures; the management of co-morbidities (hypertension, weight, dyslipidemia); and at least, good patient receptivity and accountability. Especially, the emergence of these technologies in the daily lives of diabetic patients has led to an improvement of the quality of life for patients. To date, the magnitude of its effects remains debatable, especially with the variation in patients' characteristics, samples selection and approach for treatment of control groups.
\end{abstract}

\section{Introduction}

Worldwide the number of patients with diabetes mellitus is increasing. In industrialized countries, there are estimations that diabetes is one of the leading causes of death. Today, patient with diabetes spend time each day carefully tracking blood glucose levels, food intake and physical exercise to calculate when and how much insulin should be injected into their bodies. Living with diabetes requires constant vigilance and a strong sense of self-determination and efficacy. In this context, diabetes, as many chronic diseases, benefits from both the contributions of molecular biology and innovative therapies (e.g., new insulins, immunotherapy, cellular therapy), and from major advances in technologies (e.g., sensors, infusion systems, connected objects) and in artificial intelligence (e.g., Big Data analysis) [1]. Combined with the information and communication technologies (ICT) and the social and educational sciences, these technological advances will revolutionize the care of diabetic patients in the future [2].

This short pragmatic narrative review focuses on well-established technologies, currently used in clinical routine, at the service of the diabetic patients.

\section{Current management of the diabetic patient}

To date, the management of the diabetic patient is based on a balance of his diabetes (documented by the level of haemoglobin A1c [HbAlc]) with regard to his clinical phenotype, with personalized blood glucose targets $[1,3]$. Intensive glucose control has been shown to delay or prevent the development of micro- and macrovascular complications related to diabetes [1]. In this context, optimal management of the diabetic patient is based on: patient ownership of the disease, therapeutic education, compliance with hygiene-dietary measures, therapeutic compliance and physical activity $[3,4]$. For type 1 diabetic patient, intensive insulin therapy is the reference treatment ("gold standard") [1,3]. Based on studies that have demonstrated the benefits on $\mathrm{HbAlc}$, the frequency of acute hypoglycemic and hyperglycemic episodes, the external rapid analogue infusion pump associated with the Flash Glucose MonitoringTM system (Abbott Laboratory) (Figure 1) is currently the reference management for patients undergoing intensive insulin therapy [4]. For the type 2 diabetic patient, it is imperative, in addition to the balance of diabetes (e.g. using metformin, GLP1-agonist drugs or DPP-IV inhibitors recently launched on the market) and the prevention of its complications, to properly manage comorbidities as, overweight, dyslipidemia, arterial hypertension, smoking ant sedentary lifestyle [3].

${ }^{\star}$ Correspondence to: Emmanuel Andres Service de Médecine Interne, Diabète et Maladies Métaboliques de la Clinique, Médicale B, Hôpitaux Universitaires de Strasbourg, 1, porte de l'Hôpital, 67091 Strasbourg cedex France, E-mail: emmanuel.andres@chru-strasbourg.fr

Key words: diabetes mellitus, glucose sensors, intelligent insulin pumps, artificial pancreas, telemedicine, artificial intelligence, big data

Received: February 04, 2019; Accepted: February 26, 2019; Published: March 05,2019 


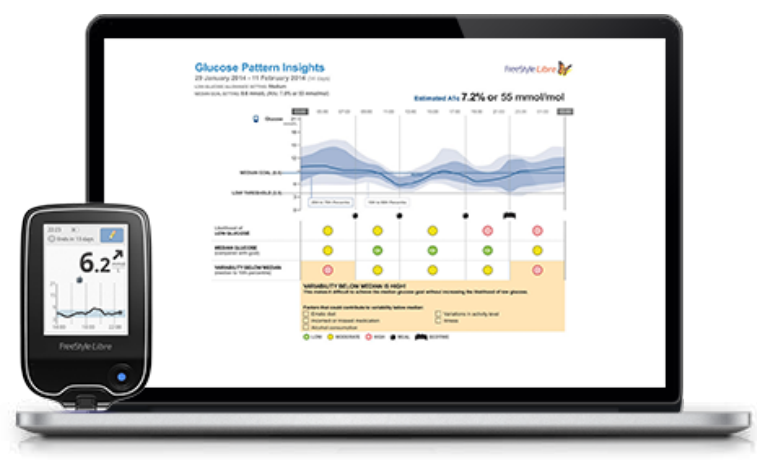

Figure 1. Flash Glucose Monitoring TM system from Abbott Laboratory

adapted from https://www.google.com/search?q=Flash+Glucose+Monitoring+system $+($ Abbott + Laboratory $) \&$ client $=$ firefox $-b-a b \&$ source $=1 n m s \& t b m=i$ sch $\& s a=X \& v e d=0 a$ hUKEwimtoSBsMLfAhUEIVAKHUhUD1cQ_AUIECgD\&biw=1920\&bih=954

\section{Non-invasive sensors for glucose self-monitoring}

For the diabetic patient, self-monitoring with a capillary blood glucose meter has long been the only way to understand his or her blood glucose control [5]. This self-monitoring gives a more or less truncated reflection of glycemic control (subject to interpretation) and above all allows the patient to adapt his insulin administration. In this setting, Holter glycaemia, followed by real-time continuous glucose measurement in the 2000s, revolutionized our vision of glycemic control [5]. In recent years, non-invasive connected sensors measuring interstitial glucose continuously have become more accurate, gradually freeing themselves from calibration constraints (e.g., Freestyle LibreTM, Abbott Laboratory), or from drug interference (e.g., paracetamol), operating for longer and longer (15 days to 6 months), and becoming more discreet by placing themselves under the skin (EversenseTM, Senseonics/Roche Diabetes Care) [5,6]. The improvement in their accuracy (meaning Mean Absolute Relative Difference [MARD], from $16-20 \%$ to $10-14 \%$ ) allows direct adaptation of insulin without concomitant control of capillary blood glucose levels [6]. Clinical studies have validated this method, which replaces the classic capillary self-monitoring of blood glucose in the management of patients treated with intensive insulin therapy. Controlled clinical studies have shown the efficacy of these devices on the improvement of HbAlc, associated with a decrease in the time spent in hypoglycemia, in type 1 diabetes under external pump, but also under multi-injection (DexCom STSTM System, Dexcom, Inc.) [6]. In addition, their efficacy has also been confirmed in type 2 diabetes, in pregnant women and in children [7]. The connection of the sensors and the possible sharing of data (Dexcom G5TM Mobile, Dexcom, Inc.), allow a joint analysis of these data by the patient, the parents of a child, the doctor or the nurse, thus avoiding, thanks to rapid adaptation of the treatment, deterioration in glycemic control. Interstitial glucose data, glycemic variability, time spent in the target defined for a patient, complete the old "hard" criteria of HbAlc and frequency of hypoglycemia. Thus new guidelines, which will be refined based on clinical studies, may propose in the near future a new definition of glycemic control assessment: "time spent in the target of $0.70-1.80 \mathrm{~g} / \mathrm{L}$ greater than $60 \%$ and time spent in hypoglycemia of less than $10 \%$ " [6]. These criteria perfectly complete HbAlc, a reflection of the glycation of the body's proteins, whose place remains to be redefined. In some industrialized countries (e.g., in France), the reimbursement by health insurance companies of these devices (e.g., FreeStyleTM Libre, Abbott laboratory) and the soon-to-be-announced reimbursement of sensors coupled to external pumps for highly unstable type 1 diabetic patients, opens the way to another modality of the concept of glycemic control assessment [5].

\section{Intelligente insulin pumps}

For type 1 and numerous type 2 diabetic patients (e.g., type 2 diabetic patients with cardiovascular complications), insulin therapy is the necessary treatment. In this setting, fast or slow insulin analogues are usually administered subcutaneously, with one or more injections per day (e.g., multiple injections in intensive therapy) [3,4]. Recent years, progress has been made with the development of ultra-fast analogues (aspart FiaspTM, Novo Nordisk Laboratory, recently launched on the French market) which allow the maximum peak action to be advanced and reduce the duration of action, and therefore the quantity of insulin "on board", by about 10 minutes [4]. They will limit the latency between flow rate changes and insulin levels in the blood, improving system performance. Nevertheless, the limitations of subcutaneous administration remain related to the still too long insulin kinetics, the reproducibility of imperfect absorption, and the absence of a first hepatic passage that is physiological. In this context, studies have been carried out with the intraperitoneal route of administration. Compared to the subcutaneous route, this latter improves the HbAlc and is associated with a decrease in the frequency of severe hypoglycemia [8]. The outer surface of the peritoneum appears to be a promising site, and some bio-artificial pancreases already use this route (e.g., BAirTM, Beta-O2 Technologies and MailPanTM for MAcrocroencapsulation of PANcreatic ILôts], Defymed Company), with kinetic and metabolic results comparable to those of the intraperitoneal route [9]. An access port device at this site allows for optimized insulin delivery either by an external pump or by injections. On this model, the device ExOlinTM (Defymed Company) is under development [10].

The connection of the EnliteTM sensor to the MiniMed VeoTM and 640GTM pumps (Medtronic Company) allows the automatic stopping of insulin infusion when a low interstitial glucose concentration is detected or predicted, dramatically reducing the occurrence of severe hypoglycemia (Figure 2) [4]. The recent reimbursement by the health insurance of this system in certain poorly balanced type 1 diabetic patients, subject to severe hypoglycemia under insulin therapy by pump and adapted self-monitoring, allows for management within the framework of the care of this precursor of the "artificial pancreas".

In this context, several "bolus calculators" have been developed, especially for the insulin pumps, offering a bolus dose by coupling the current blood glucose level and a predetermined insulin/glucose ratio [2]. Nowadays, these systems have been replaced by new intelligent

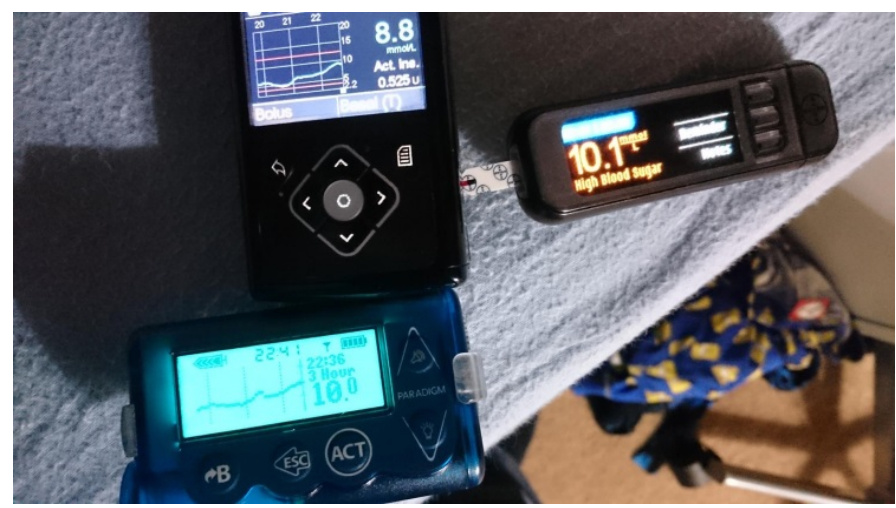

Figure 2. EnliteTM sensor - MiniMed VeoTM - 640GTM pumps from Medtronic Company adapted from: https://www.google.com/search?client=firefox-b-ab\&bi $\mathrm{w}=1920 \& \mathrm{bih}=954 \& \mathrm{tbm}=\mathrm{isch} \& \mathrm{sa}=1 \& \mathrm{e} i=\mathrm{SQgmXLq} 4 \mathrm{JsnkkgWAq} 53 \mathrm{wC}$ w \& $q=$ MiniMed+Veo+and $+640 \mathrm{G}+\&$ oq $=$ MiniMed+Veo+and $+640 \mathrm{G}+\&$

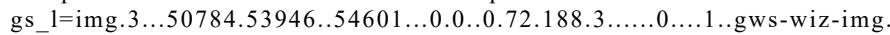
$\mathrm{UjQ}$ _2YH35qw\#imgrc $=\mathrm{h} 50 \mathrm{~L}-\mathrm{In} 2 \mathrm{D} 0 \mathrm{oL} 2 \mathrm{M}$ 
systems based on algorithms (artificial intelligence [AI]) [2,7]. These latter make it possible to propose a real adaptation of prandial and basal doses by integrating several parameters (glycaemia, insulin sensitivity, etc.) specific to the patient phenotype (personalized medicine). Self-learning, they are specifically adapted to the patient's history of glycemic variations. They have shown their effectiveness on HbA1c, without increasing hypoglycemia, especially when coupled with nursing "coaching" (DiabeoTM, Sanofi Laboratory) [11]. This system is currently approved within the framework of telemedicine [X]. Coupled with an external 670GTM pump (Medtronic Company), other algorithms already allow automatic adaptation of basal rates, with the patient managing only bolus doses [7].

\section{Artificial pancreas for glycemic management}

The rise of all these technologies that we have just seen has led to the recent appearance of the "artificial pancreas", the "diabetic patient's dream" [12]. Since the demonstration, in 2015, of its efficacy in ambulatory care, the results of 24 studies on 585 patients, compiled in a recent meta-analysis, have confirmed a significant improvement in the time spent in the target, the reduction of HbAlc and mean blood glucose, without an increase in hypoglycemia $[12,13]$. To date, the artificial pancreas is based on a closed-loop insulin delivery system, integrating AI. Most of these devices are mono-hormonal (insulin) and semi-automatic, with the patient manually reporting food intake and physical activity. Many of these devices are expected to be quickly brought to market (e.g., DiabeloopTM from Medtech Company) [14]. The limitations of single-hormonal subcutaneous devices are related to sensor latency, kinetics of interstitial glucose changes, and reproducibility of peripheral administration of subcutaneous insulin.

In this setting, the bi-hormonal approach (insulin-glucagon), poses technical problems, as the stability of glucagon and the necessity of double reserves, but seems interesting to avoid hypoglycemia, especially during physical exercise $[12,13]$. The addition of amylin or glucagonlike peptide-1 (GLP1) receptor analogue improves post-meal blood glucose levels by decreasing glucagon secretion; future years should make it possible to clarify the place of these molecules in the artificial pancreas.

Another approach would be to operate other sites that combine sensors and insulin delivery. A study combining a subcutaneous sensor and intraperitoneal insulin infusion showed better regulation of postmeal periods [15]. Intraperitoneal insulin, which is more physiological, could improve problems related to meals and physical activity. Projects to miniaturize the implantable system and reduce its cost are all assets for make it an attractive alternative.

Improving the skills and the capacities of algorithms, by using the databases set up (big data analysis), optimizing their self-learning capacity, their patient-specific adaptation capacity, and supplementing their information with multiple sensors collecting parameters other than blood glucose levels, could allow early detection of food intake, physical activity, stress, and adaptation of the system to specific situations (children, pregnancies, highly unstable diabetes) [16]. The connection of the system to a telemedicine and coaching platform is an evolution that is already underway in the system DiabeloopTM.

\section{Telemedicine for diabetic patients}

Since the early 1990s to the end of the 2010's, numerous telemedicine projects and studies have been developed in the field of diabetes [2]. Practically all of them have investigated telemonitoring in specific diabetic patients (children and young people, elderly patients, patients with intensified therapy, patients under insulin pump therapy and patients with complicated or complex diabetes). The results of these telemedicine projects (including type 1 and type 2 diabetic patients, involving the upload and direct transmission of blood-glucose data by diabetic patients to providers via cellular telephone, telephone land line, or a Web-based program) differed from study to study, with fairly inconclusive results as to their potential clinical benefits in terms of balancing diabetes (Table 1) [17]. This is also the case in terms of: the management of associated-metabolic problems and comorbidities; re-hospitalization; and decreased morbidity or mortality, particularly regarding the statistical significance of the results.

Over the last ten years, "new" generation telemedicine projects and studies have been developed in the setting of diabetes management [2]. These projects and studies have for main objectives to evaluate the use of technology to implement medical and cost-effective health care management on a large scale for diabetes management. Compared to the first projects, most of these new generation projects incorporate: self-administered medical questionnaires or forms on: symptoms, signs of diabetes decompensation; tools for medical education, particularly disease self-appropriation, food hygiene, and physical activity; tools for patient motivation; tools for therapeutic and hygiene observance; tool to remote comorbidities (e.g. arterial hypertension, obesity, dyslipidemia); tools for interaction between the patient and healthcare professionals like telephone support centres, tablets, and Web-sites (Figure 3) [2].

The analysis of these different projects and studies shows that remote monitoring (telemonitoring) showed: improvements in control of blood glucose level, significant reduction in $\mathrm{HbAlc}$; better appropriation of the disease by patients; greater adherence to therapeutic and hygiene-dietary measures; positive impact on comorbidities (arterial hypertension, weight, dyslipidemia); better patient's quality of life; and at least, good receptiveness by patients and patient empowerment [2]. Moreover, a cost-effectiveness analysis found a potential of medical economy. However to date, the magnitude of its effects remains debatable, especially with the variation in patients' characteristics (e.g. background, ability for self-management, medical condition), samples selection and approach for treatment of control groups.

Over the last 5 years, new-generation telemedicine projects and studies have emerged in the setting of type 1 and type 2 diabetes $[2,11,18,19]$. They support transmission and remote interpretation of patients' data for follow-up and preventive interventions. These new generation telemedicine projects are often known as "telemedicine 2.0" projects, given that they all utilize new Information and Communication Technologies (ICT) and the Web (tools for the "e-Health 2.0") [20]. These projects rely on the standard connected tools for monitoring diabetes, such as glucose meters, $\mathrm{BP}$, heart rate monitors, weighing scales, and pulse oximeters, which relay the collected information via Bluetooth, $3 \mathrm{G}$ or $4 \mathrm{G}[2,21]$. They include continuous glycemic monitoring solution and often a video-call.

\section{Artificial intelligence for diabetes management}

In recent years, several informatics solutions or tools have been developed and used to optimize the management of chronic disease, such as: Artificial Neural Networks (ANN) algorithms, data mining software, ontology $[2,22]$. These solutions or tools are called artificial intelligence (AI). For this later, three clinical datasets are of particular interest: 1) patients' phenotype; 2) patients' electronic medical records containing physicians' notes, laboratory test results, as well as other information on diseases, treatments, and epidemiology that may be of interest for association studies and predictive modelling on 
Table 1. Results of the telemonitoring studies conducted in the field of diabetes during the period from 2010 to 2015 [2,17]

\begin{tabular}{|c|c|}
\hline Name of the study & Results \\
\hline $\begin{array}{l}\text { The Utah Remote Monitoring } \\
\text { Project } \\
(\mathrm{n}=109)\end{array}$ & $\begin{array}{l}\text { Principal criteria: } \\
\text { - } \quad \text { Mean HbAlc had decreased from } 9.73 \% \text { at baseline to } 7.81 \% \text { at the end of the program }(p<0.0001) \\
\text { - } \quad \text { Systolic blood pressure (BP) had decreased from } 130.7 \mathrm{mmHg} \text { at baseline to } 122.9 \mathrm{mmHg} \text { at the end }(p=0.0001) \\
\text { Secondary criteria: } \\
\text { - } \quad \text { Low-density lipoprotein content had decreased from } 103.9 \mathrm{mg} / \mathrm{dL} \text { at baseline to } 93.7 \mathrm{mg} / \mathrm{dL} \text { at the end }(p=0.0263) \\
\text { - } \quad \text { Knowledge of diabetes and arterial hypertension have increased significantly ( } p<0.001 \mathrm{for} \text { both). } \\
\text { - } \quad \text { Patient engagement and medication adherence also have improved, but not significantly } \\
\text { - } \quad \text { Per questionnaires at study end, patients felt the telemonitoring program had been useful. }\end{array}$ \\
\hline $\begin{array}{l}\text { Randomized Trial on Home } \\
\text { Telemonitoring for the } \\
\text { Management of Metabolic } \\
\text { and Cardiovascular Risk in } \\
\text { Patients with type } 2 \text { Diabetes } \\
(\mathrm{n}=302)\end{array}$ & $\begin{array}{l}\text { Principal criteria: } \\
\text { - Mean HbAlc difference of } 0.33 \pm 0.1(p=0.001) \text { have been observed between the telemonitoring compared and the control group. The } \\
\text { proportion of patients reaching the target of HbAlc }(\mathrm{HbA} 1 \mathrm{c}<7.0 \%) \text { had been higher in the telemonitoring group than in the control group } \\
\text { after } 6 \text { months: } 33.0 \% \text { vs. } 18.7 \%(p=0.009) \text { and } 12 \text { months: } 28.1 \% \text { vs. } 18.5 \%(p=0.07) \text {. } \\
\text { - } \quad \text { No difference had been registered for body weight, BP, and lipid profile } \\
\text { Secondary criteria: } \\
\text { - } \quad \text { For quality of life (evaluated with the } 36 \text {-item Short Form health survey), significant differences in favor of the telemonitoring group, as for } \\
\text { physical functioning }(p=0.01) \text { and mental health ( } p=0.005) \text {. } \\
\text { - On an economic level, a lower number of specialist visits was reported in the telemedicine group: incidence rate ratio of } 0.72(95 \% \\
\text { confidence interval, } 0.51-1.01 ; p=0.06) \text {. }\end{array}$ \\
\hline $\begin{array}{l}\text { Study assessed the utility } \\
\text { and cost-effectiveness of an } \\
\text { automated Diabetes Remote } \\
\text { Monitoring and Management } \\
\text { System (DMRS) } \\
(\mathrm{n}=98)\end{array}$ & $\begin{array}{l}\text { Principal criteria: } \\
\text { - No significant difference for mean HbA1c between the DRMS and control groups at } 3 \text { months: } 7.60 \% \text { vs. } 8.10 \% \text { and at } 6 \text { months: } 8.10 \% \text { vs. } \\
7.90 \% \text { ( } p=\text { ns) } \\
\text { Secondary criteria: } \\
\text { - } \quad \text { Changes from baseline to } 6 \text { months have been not statistically significant for self-reported medication adherence } \\
\text { - Changes of diabetes-specific quality of life have been not significant registered, except for the Daily Quality of Life-Social/Vocational } \\
\text { Concerns subscale score }(p=0.04)\end{array}$ \\
\hline $\begin{array}{l}\text { Telescot Diabetes Pragmatic } \\
\text { Multicenter Randomized } \\
\text { Controlled Trial } \\
(\mathrm{n}=321)\end{array}$ & $\begin{array}{l}\text { Principal criteria: } \\
\text { - The Mean (SD) HbA1c at follow-up was } 7.92 \% \text { in the intervention group vs. } 8.36 \% \text { in the usual care group]. For primary analysis, adjusted } \\
\text { mean HbA1c was } 0.51 \% \text { lower ( } 95 \% \text { CI } 0.22 \% \text { to } 0.81 \% \text {, (principal criterion) }(p=0.0007) \\
\text { Secondary criteria: } \\
\text { - } \quad \text { Adjusted mean ambulatory systolic BP has been } 3.06 \mathrm{mmHg} \text { lower }(95 \% \text { CI } 0.56-5.56 \mathrm{mmHg}, p=0.017) \text { and mean ambulatory diastolic } \\
\text { BP has been } 2.17 \mathrm{mmHg} \text { lower ( } 95 \% \text { CI } 0.62-3.72, p=0.006) \text { among people in the intervention group when compared with usual care after } \\
\text { adjustment } \\
\text { - } \quad \text { No significant differences were identified between groups in terms of: weight, treatment pattern, adherence to medication or quality of life } \\
\text { - The number of telephone calls was greater between nurses and patients in the intervention compared with control group: rate ratio of } 7.50 \\
(95 \% \text { CI } 4.45-12.65, p<0.0001) \text { but no other significant differences between groups in use of health services were identified between groups }\end{array}$ \\
\hline
\end{tabular}

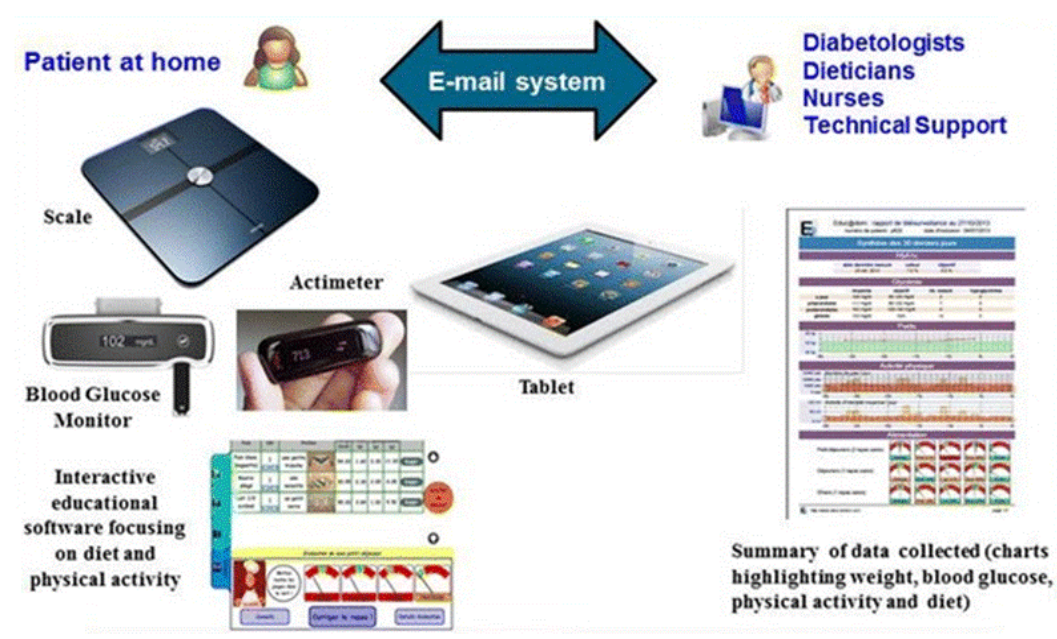

Figure 3. Telemedicine project: Educ@dom

adapted from https://www.google.com/search?q=telemonitoring+diabetic+patient\&client=firefox-b\&source=lnms\&tbm=isch\&sa=X\&ved=0ahUKEwj6h92uuMLfAhWPzKQKHclfAh kQ_AUIDigB\&biw $=1920 \& b i h=918 \#$ imgrc $=0$ Eh6raxPEr0VFM 
prognosis and drug responses; and 3) literature knowledge including rules on diabetes management. In the setting of diabetes, two of the aforementioned telemedicine projects use AI in order to be able: firstly, to adjust the blood glucose level to the patient's activity (software DiabeoTM, Sanofi Laboratory) [11]; and secondly, to predict patient risks of diabetes decompensation [23]. In this later situation, the cloudbased software aggregates, cleans, and analyzes patient data to allow for identifying patterns that may indicate potential risks and provide predictive insights on healthcare outcomes, as the software MyPrediTM (Predimed Technology Company) [23].

In the TELESAGE study, type 1 diabetic patients were randomized to usual quarterly follow-up (G1), home use of a smartphone recommending insulin doses (DiabeoTM software) with quarterly visits (G2), or use of the smartphone with short teleconsultations every 2 weeks but no visit until point end (G3) [11,19]. At six-month, the mean HbA1c level: $8.41 \pm 1.04 \%$ in G3 vs. $8.63 \pm 1.07 \%$ in G2 vs. $9.10 \pm 1.16 \%$ in $\mathrm{G} 1$ ( $\mathrm{p}=0.0019$ for G1-G3 comparison) (Figure 4) [40,41]. The DiabeoTM system gave a $0.91 \%(0.60-1.21)$ improvement in HbA1c over controls and a $0.67 \%(0.35-0.99)$ reduction when used without teleconsultation. There was no difference in the frequency of hypoglycemic episodes or in medical time spent for hospital or telephone consultations. However, patients in G1 and G2 spent nearly $5 \mathrm{~h}$ more than G3 patients attending hospital visits.

The DIABETe telemonitoring project, has been developed and designed to optimize home monitoring of diabetic patients by detecting, via a telemonitoring 2.0 platform, situations with a risk of decompensation of diabetes and its complications (e.g., myocardial infarction or chronic heart failure), the latter ultimately leading to hospitalization [23]. The AI of the DIABETe platform (MyPrediTM) automatically generates indicators of "health status" deterioration, i.e., "warning alerts" for any chronic disease worsening, particularly diabetes, its macrovascular complications and cardiovascular comorbidities (e.g., arterial hypertension, chronic heart failure). For the patient, these situations may lead to hospitalization if not treated appropriately.

To our knowledge, this is one of the first projects that use AI in addition to ICT. The platform comprises connected nonintrusive medical sensors, a touchscreen tablet connected by $\mathrm{Wi}$ - $\mathrm{Fi}$, and a router or $3 \mathrm{G} / 4 \mathrm{G}$, rendering it possible to interact with the patient and provide education on treatment, diet, and lifestyle (Figure 5) [23].

The telemonitoring platform used in DIABETe was first validated in a monocentric study conducted in the Strasbourg University Hospital, carried out as part of the E-Care project, primarily focused on the problem of chronic heart failure [24]. Between February 2014 and April 2015, 175 patients (mean age of 72 years) were included into the E-care project, $30 \%$ of these patients suffered from type 2 diabetes. During this period, the telemonitoring platform was used on a daily basis by patients and healthcare professionals, according to a defined protocol of use specific to each patient. During the study, 1,500 measurements were taken, generating 700 alerts in 68 patients. 107 subjects $(61.1 \%)$ had no alerts upon follow-up. Analysis of the warning alerts in the 68 other patients showed that MyPrediTM detected any worsening of the "patient's health", with a sensitivity, specificity, as well as positive and negative predictive values of: $100 \%$, $30 \%, 89 \%$ and $100 \%$, respectively. In this experimentation, both
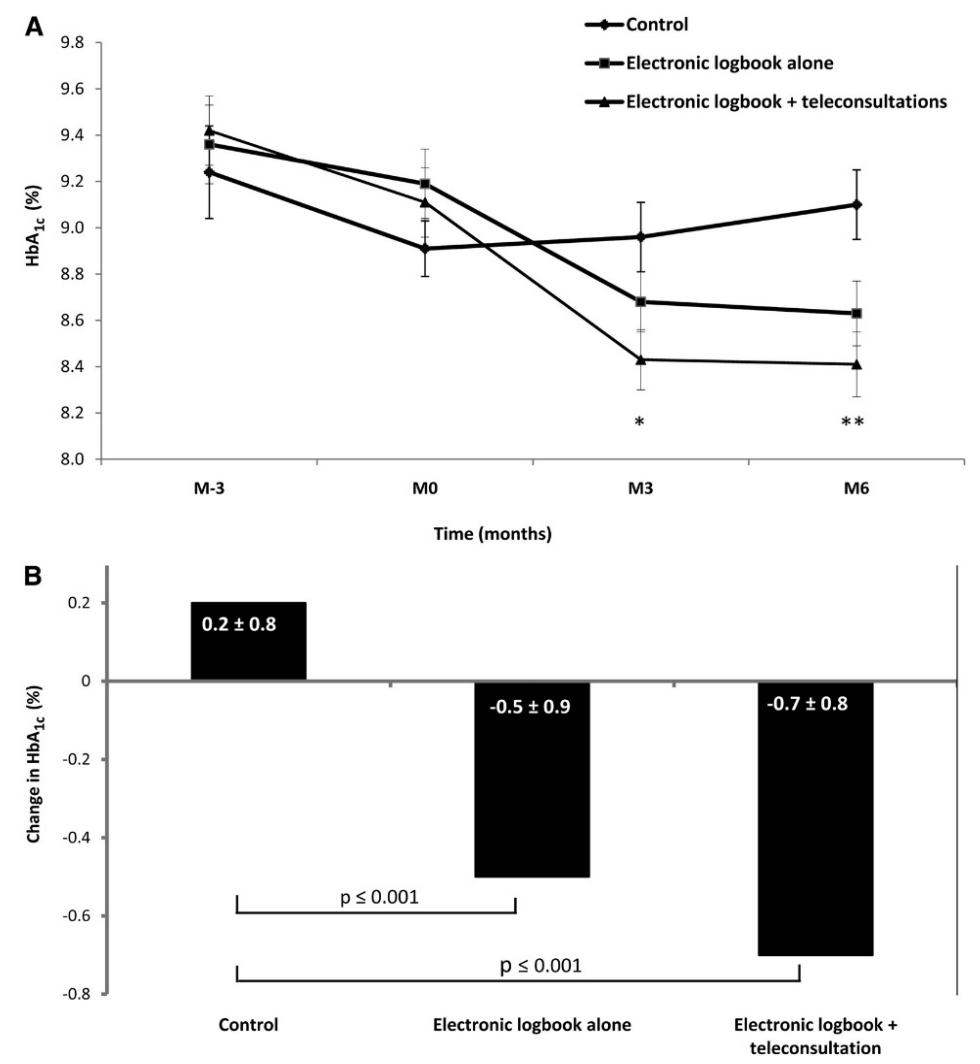

Figure 4. Efficacy of the software DiabeoTM, licensed by Sanofi Laboratory

(adapted from [19]). A: HbA1c values (means $\pm \mathrm{SE}$ ), from 3 months before baseline to month $6 .{ }^{*} \mathrm{p}=0.0103,{ }^{* *} \mathrm{p}=0.0019$ compared with control group. B: Change in HbA1c values (means $\pm \mathrm{SE}$ ) from baseline to month 6 

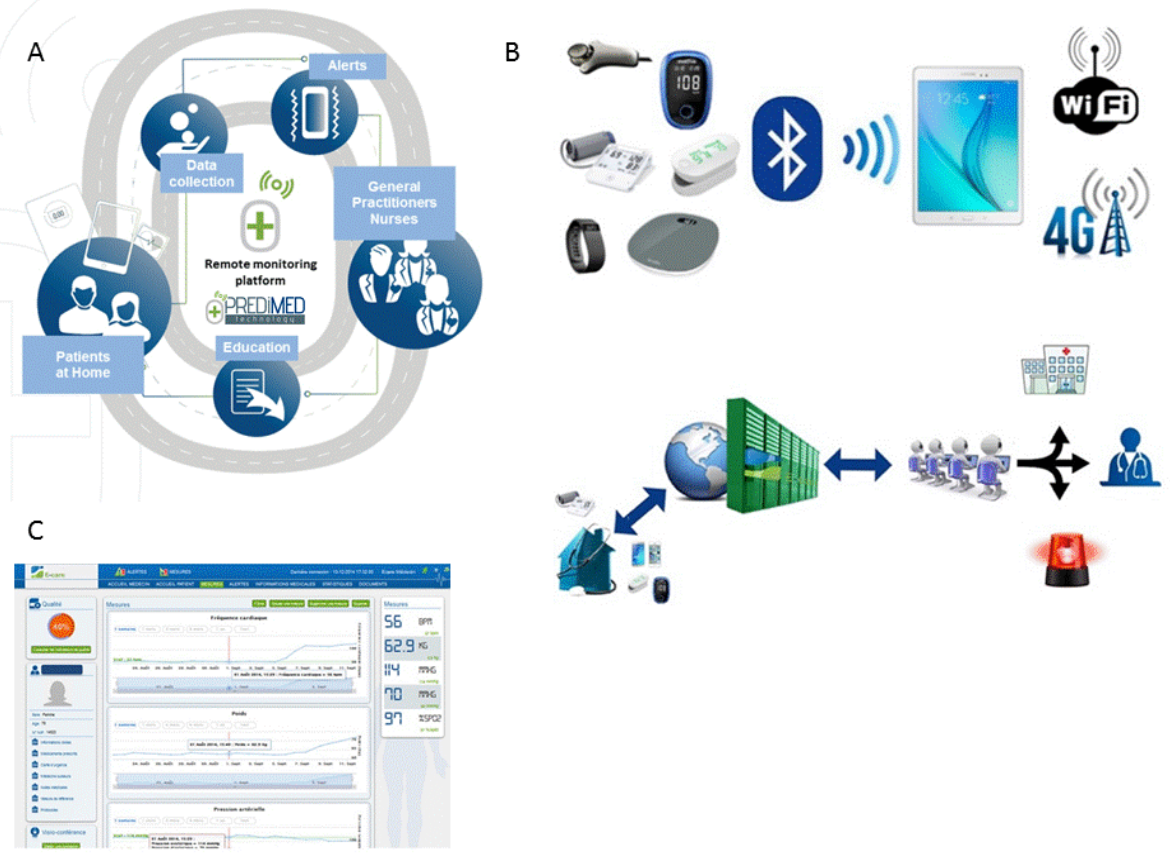

Figure 5. Telemedicine project: DIABETe. A: DIABETe is based on a smart system comprising an inference engine and a medical ontology for personalized synchronous or asynchronous analysis of data specific to each patient and, if necessary, the sending of an artificial intelligence-generated alert (MyPredi ${ }^{\mathrm{TM}}$. B: The platform comprises connected nonintrusive medical sensors, a touchscreen tablet connected by Wi-Fi, and a router or $3 \mathrm{G} / 4 \mathrm{G}$, rendering it possible to interact with the patient and provide education on treatment, diet, and lifestyle. C: The system involves a server that hosts the patient's data and a secure internet portal to which the patient and hospital- and non-hospital-based healthcare professionals can connect

the healthcare professionals and patients, even the frailest, used the E-care system without difficulty until the end of the study.

In this setting of IA, all new connected sensors collect data on a daily basis, which are stored and analyzed by Big Data algorithms such as Machine Learning, which will make it possible to predict risk situations, investigate their causes and highlight new alternatives for care procedures [22]. The aim is to draw the caregiver's attention to the right patient at the right time and thus avoid an emergency consultation or even hospitalization.

\section{Conclusions}

This short pragmatic narrative review supports the efficacy of numerous technologies as non-invasive glucose sensors, intelligent insulin pumps, artificial pancreas, telemedicine, AI, in diabetic patients. Mainly, these technologies have shown a beneficial effect on diabetes management with an improvement of: blood glucose control, with a significant reduction in $\mathrm{HbAlc}$; patient ownership of the disease; patient adherence to therapeutic and hygiene-dietary measures; the management of co-morbidities (hypertension, weight, dyslipidemia); and at least, good patient receptivity and accountability. Especially, the emergence of these technologies in the daily lives of diabetic patients has led to an improvement of the quality of life for patients. To date, the magnitude of its effects remains debatable, especially with the variation in patients' characteristics, samples selection and approach for treatment of control groups.

Innovative technologies based on AI (machine learning, Big Data) are going to build the future of diabetology; fully automated artificial pancreas, telemedicine interventions preventing severe glucose degradations and helping with diabetes burden in a day-to-day basis. Moreover, these technologies will also be a major source to understand mechanisms of disease degradation and psychology and behavior of patients who have to cope with this. This will lead to a new optimized way of patient and disease management. Diabetologists will have to adapt to this new world.

\section{Fundings}

Grants from the Agence Régionale de Santé du Grand-Est (ARS).

\section{Consent and ethical approval}

Not applicable.

\section{Competing interest}

M. Hajjam is the scientific director of Predimed Technology (www. predimed-technology.fr). All other authors have declared that no competing interests exist.

\section{Guarantor}

EA.

\section{Contributorship}

$\mathrm{EA}, \mathrm{MH}$ and $\mathrm{NJ}$ designed the paper and conducted the literature searches. EA, NJ, LM, and MH drafted the results and parts of the discussion. TB, AAZ, ST and AEHH provided critical analysis, revised the whole manuscript, and approved the final version for publication. EA is responsible for all revisions and remains in contact with the rest of the review team regarding status reports.

\section{References}

1. Bartlett ST, Markmann JF, Johnson P (2016) Report from IPITA-TTS opinion leaders meeting on the future of $\beta$-cell replacement. Transplantation 100: S1-S44. [Crossref]

2. Andrès E, Hajjam M, Talha $\mathrm{S}$ (2018) Télémédecine dans le domaine de l'insuffisance cardiaque. État des lieux et focus sur le projet de télémédecine 2.0 E-care. Perspectives dans le domaine de la diabétologie. Médecine des Maladies Métaboliques 12: 224-31. 
3. Nathan DM (2015) Diabetes: Advances in diagnosis and treatment. JAMA 314: 1052 1062. [Crossref]

4. Benhamou PY, Lablanche S (2018) Diabete de type 1: perspectives technologiques. MCED 92: 11-16.

5. Rodbard D (2017) Continuous glucose monitoring: A review of recent studies demonstrating improved glycemic outcomes. Diabetes Technol Ther 19: S25-S37. [Crossref]

6. Borot S, Benhamou PY, Atlan C (2018) Société francophone du diabète (SFD), Société française d'endocrinologie (SFE), Evaluation dans le diabète des implants actifs Group (EVADIAC). Practical implementation, education and interpretation guidelines for continuous glucose monitoring: A French position statement. Diabetes Metab 44: 61-72.

7. Biester T, Kordonouri O, Holder M (2017) "Let the algorithm do the work": reduction of hypo- glycemia using sensor-augmented pump therapy with predictive insulin suspension (SmartGuard) in pediatric type 1 diabetes patients. Diabetes Technol Ther 19: 173-182. [Crossref]

8. Barrientos R, Baltrusch S, Sigrist S, Legeay G, Belcourt A, et al. (2009) Kinetics of insulin secretion from MIN6 pseudoislets after encapsulation in a prototype device of a bioartificial pancreas. Horm Metab Res 41: 5-9. [Crossref]

9. https://www.defymed.com/mailpan/ [December 27, 2018]

10. https://www.defymed.com/exolin/ [December 27, 2018].

11. Jeandidier N, Chaillous L, Franc S (2018) DIABEO app software and telemedicine versus usual follow-up in the treatment of diabetic patients: Protocol for the TELESAGE randomized controlled trial. JMIR Res Protoc 7: e66. [Crossref]

12. Castle JR, DeVries JH, Kovatchev B (2017) Future of automated insulin delivery systems. Diabetes Technol Ther 19: S67-S72. [Crossref]

13. Bertachi A, Ramkissoon CM, Bondia J, Vehí J (2018) Automated blood glucose control in type 1 diabetes: A review of progress and challenges. Endocrinol Diabetes Nutr 65: 172-181. [Crossref]

14. Christiansen SC, Fougner AL, Stavdahl O (2017) A review of the current challenges associated with the development of an artificial pancreas by a double subcutaneous approach. Diabetes Ther 8: 489-506.
15. Renard E, Place J, Cantwell M (2010) Closed- loop insulin delivery using a subcutaneous glucose sensor and intraperitoneal insulin delivery: feasibility study testing a new model for the artificial pancreas. Diabetes Care 33: 121-127.

16. Aleppo G, Webb K (2018) Continuous glucose monitoring integration in clinical practice: A stepped guide to data review and interpretation. J Diabetes Sci Technol. [Crossref]

17. Andrès E, Talha S, Jeandidier N, Meyer L, Hajjam M, et al. (2018) Telemedicine in chronic diseases: the time of maturity with telemedicine 2.0 in the setting of chronic heart failure and diabetes mellitus. Curr Res Diabetes Obes J 6: 1-4.

18. Lindberg I, Torbjørnsen A, Soderberg S, Ribu L (2017) Telemonitoring and health counselling for self-management support of patients with type 2 diabetes: A randomized controlled trial. JMIR Diabetes 2: e10.

19. Charpentier G, Benhamou PY, Dardari D (2011) TeleDiab study group. The Diabeo software enabling individualized insulin dose adjustments combined with telemedicine support improves $\mathrm{HbA} 1 \mathrm{c}$ in poorly controlled type 1 diabetic patients: a 6-month, randomized, open-label, parallel-group, multicentre trial (TeleDiab 1 Study). Diabetes Care 34: 533-539.

20. Van De Belt TH, Engelen LJ, Berben SA, Schoonhoven L (2010) Definition of health 2.0 and medicine 2.0: a systematic review. J Med Internet Res 12: e18. [Crossref]

21. Puricel SG, Ruiz J (2014) Diabetes mellitus and the era of telemedicine. Rev Med Suisse 10: 1246-1248. [Crossref]

22. Rjeily CB, Badr G, El Hassani AH, Andrès E (2018) Medical data mining for hear diseases and the future of sequential mining. Machine learning paradigms: advances in data analytics 149: 71-99.

23. https://www.predimed-technology.fr/solutions/plateforme-intelligente-my-predi/ [December 27, 2018].

24. Andrès E, Talha S, Hajjam M, Hajjam J, Ervé S, et al. (2018) Experimentation of 2.0 telemedicine in elderly patients with chronic heart failure: A study prospective in 175 patients. Eur J Intern Med 51: e11-11e12. [Crossref]

Copyright: (C2019 Andrès E. This is an open-access article distributed under the terms of the Creative Commons Attribution License, which permits unrestricted use, distribution, and reproduction in any medium, provided the original author and source are credited. 